\title{
Gastrointestinal robotic surgery: challenges and developments
}

This article was published in the following Dove Press journal:

Robotic Surgery: Research and Reviews

30 January 2015

Number of times this article has been viewed

\author{
Lapo Bencini \\ Mario Annecchiarico \\ Michele Di Marino \\ Luca Moraldi \\ Federico Perna \\ Andrea Coratti \\ Division of Surgical Oncology and \\ Robotics, Department of Oncology, \\ Careggi University Hospital, \\ Florence, Italy
}

Correspondence: Lapo Bencin

Division of Oncologic Surgery and

Robotics - Department of Oncology,

Azienda Ospedaliero-Universitaria di

Careggi, Largo Brambilla 3, Florence, Italy

Tel +39055 7947404

Fax +39055 794745 I

Email lapbenc@tin.it

\begin{abstract}
The rapid diffusion of new technologies in surgery, together with high expectations of both patients and the mass media, has led to many gastrointestinal procedures being approached using robots. Robotic technology seems to resolve many of the drawbacks of laparoscopic advanced procedures, such as anastomotic reconstructions, accurate lymphadenectomy, and vascular sutures. In addition, a deeper tridimensional steady vision with excellent high definition, the EndoWrist technology offering seven degrees of freedom, tremor filtration, scaled motion, optimal working ergonomics, and avoidance of the 'fulcrum effect', are the main strengths of the da Vinci ${ }^{\circledR}$ system. The use of near-infrared technology and the possibility of tutoring through a double-console will most likely add many more advantages of this technology over laparoscopy alone. However, none of the gastrointestinal robotic interventions has reached a level of evidence-based efficacy that enables it to be routinely applied. The main limitations of robotic gastrointestinal procedures are represented by the learning curve, the higher costs of robotic surgery compared to traditional and laparoscopic surgery, and the longer operation times, including setup and organizational troubles. Moreover, while the limits of robotics for benign diseases are mainly represented by technical issues, oncologic outcomes remain the foundation of any procedures to cure malignancies, and long-term follow-up is still lacking. On the other hand, a word of caution should be presented on the adoption of robotics in too many surgical units without the correct and formal technical background and third-party control to guarantee the best outcomes for patients at minimum risk. Therefore, the robotic treatment of gastrointestinal diseases requires a thorough analysis of the published evidence, in order to determine the correct indications and patient selection. This review aims to examine the evidence for the use of robotic surgery in both malignancies and benign disease arising from the gastrointestinal area. Future developments in robotics and ongoing areas of research are also analyzed.
\end{abstract}

Keywords: gastrointestinal surgery, mini-invasive surgery, da Vinci

\section{Introduction}

Gastrointestinal surgery represents a large field for the application of mini-invasive technologies, and gastrointestinal surgeons have contributed, to a large degree, to the widespread adoption of laparoscopy among almost all the hospitals worldwide. Conversely, the merit of the penetration of robotic surgery (RS) in the surgical community is mainly attributable to urologists. ${ }^{1}$ In the last few years, there has been widespread adoption of robotic prostatectomy, particularly among high-volume surgeons, which has been associated with a centralization of care and increased economic burden for prostate cancer surgery. ${ }^{2}$

The da Vinci Robot system has been approved for clinical use in the US since $2000 .^{3}$ However, as of 2009, according to a large database, very few gastrointestinal 
procedures have been approached in this way, even though early studies have reported better results in terms of the reduction of hospital stay and perioperative deaths compared to open surgery (less than laparoscopy). ${ }^{4}$ The following three main barriers to the adoption of robotics for both user and nonuser surgeons have been found to be perceived: low ease of use, usefulness, and control according to a structured questionnaire. ${ }^{5}$

The reasons for this delay could have several explanations. Firstly, the wider gastrointestinal spectrum of procedures with many reconstructive steps has led to challenging learning curves with peculiar anesthetic implications. ${ }^{6}$ Moreover, when applying criteria of Health Technology Assessment (HTA), RS has been shown to have higher costs related to the purchase and maintenance of technology and longer operating room time compared to the other approaches. ${ }^{7}$ Lastly, the optimum level that has been achieved for some pure laparoscopic gastrointestinal techniques has caused much resistance to the development of a newer complex technology.

Apart from the well-known intrinsic difficulties of surgical research, all these issues could also explain why none of the gastrointestinal robotic interventions have reached a level of evidence-based efficacy that enables it to be routinely applied. ${ }^{8}$ Nevertheless, the progressive popularity of RS among urologists, gynecologists, and patients, mixed with some industrial pressure, has led to the worldwide diffusion of the robot in many hospitals. ${ }^{9}, 10$

Interestingly, the pioneers ${ }^{11,12}$ of general and gastrointestinal RS reported many benefits and few complications of this technique in terms of intraoperative morbidity, return to normal activities and, mainly, feasibility of some of the most complex procedures that were previously precluded by pure laparoscopy without the robotic interface. Moreover, when considering the overall costs in high-volume centers, including reduction of complications and length of stay (LOS), many robotic procedures could become cost-effective except for very simple routine operations, such as cholecystectomy and esophagogastric junction functional surgery. ${ }^{13,14}$

Nevertheless, many of the initial experiences were anecdotal and performed by only a few experienced surgeons, while most of the results were hardly applied out of each single experience. ${ }^{11,15}$

The main advantages of the robotic system are represented by better ergonomic surgeon position, deeper high-definition 3D vision, EndoWrist arm technology (articulation of the instruments with seven degrees of freedom), motion scaling, and tremor filtration. Other additional applications of robotics are the use of near-infrared technol- ogy (so-called Firefly) and the possibility of tutoring through a double-console, ${ }^{16}$ while many others have shown its utility in prospective applications (picture-in-picture preoperative and intraoperative imaging, haptic feedback, EndoWrist harmonic scalpel) (Figure 1). ${ }^{17}$

Interestingly, some concurrent companies, in addition to the only market competitor (Intuitive Surgical, Inc.), have been developing alternative robotic systems, which could lead to some cost reduction.
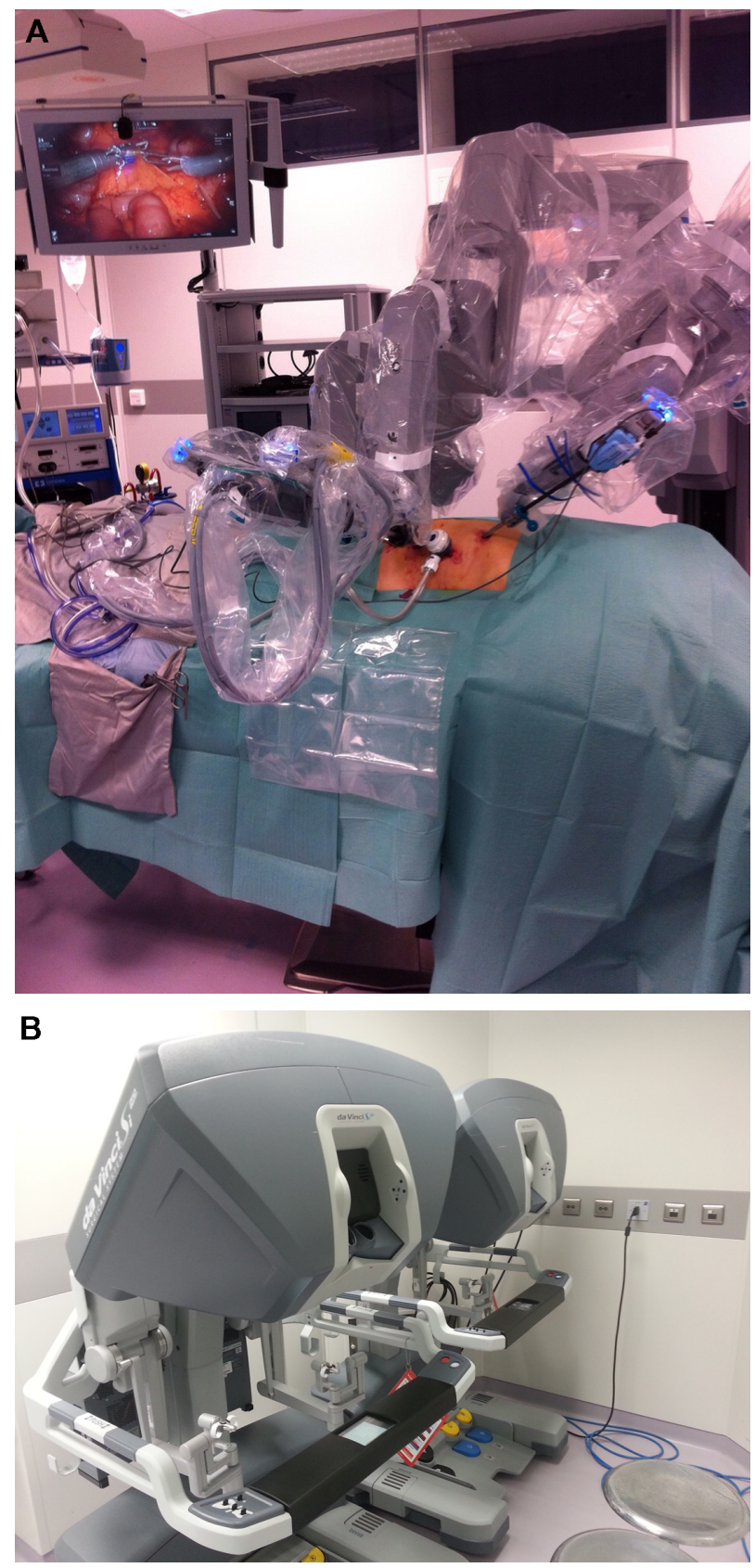

Figure I The setting of the da Vinci robotic system (A) during a right colon resection at the Careggi University Hospital; and the surgeon console (B). 
However, if the limits of the widespread adoption of RS are mainly represented by technical issues, learning curves, and costs, oncologic outcomes remain the foundation of most of the gastrointestinal procedures..$^{18}$ Any mini-invasive operation, whether laparoscopically or robotically performed, should follow the same oncologic principles of open surgery, generally limiting the skills gain to high-volume centers with subspecialized teams. ${ }^{19}$ Furthermore, from an ethical point of view, the application of a full robotic program should follow a few important principles for safety and nonmaleficence, in order to guarantee the maximum safety of each patient during the gaining learning curve. ${ }^{20}$

We focused this review on the full robotic (and some hybrid techniques) treatment of gastrointestinal diseases, including those arising from the esophagus, stomach, liver and biliary system, pancreas, and colorectum, as well as some other miscellaneous techniques (ie, bariatric surgery). If not otherwise specified, the robotic equipment was the da Vinci System $^{\circledR}$ (Intuitive Surgical, Inc.).

A search of the PubMed, EMBASE, and Cochrane databases was conducted until September 2014, including important cross-matched manual references. Randomized controlled clinical trials (RCTs) or meta-analyses were considered a priority. Data arising from English-written, multicentric, international studies, and those with long-term follow-up and oncologic results were also considered of utmost interest, rather than the feasibility of one procedure itself or short-term outcomes.

\section{Esophagus}

The minimally invasive surgery of benign and malignant pathology of the esophagus and gastroesophageal junction remains a challenge, although the development and distribution of the robotic platform has allowed an enhancement and improvement of the traditional surgical practice.

A few rigorous articles have been published on the robotic approach to benign disease of the esophagus, and most compared it with open or laparoscopic technique. However, the recent introduction of pure endoscopic techniques and well-established efficacy of medical therapy should lead to a theoretical five arms of study (medical vs endoscopic vs open surgery vs laparoscopy vs robotics), although such studies are very hard to design and to conduct. ${ }^{8}$

All the esophageal procedures for benign disease were codified with a robotic approach, including those for achalasia, reflux disease, and diverticula. ${ }^{21}$

A very large retrospective study by Shaligram et $\mathrm{al}^{22}$ on 2,683 patients with achalasia, 419 of which underwent
Heller myotomy by open surgery (OM), 2,116 underwent laparoscopic approach (LM), and 149 underwent robotic approach (RM) surgery. No differences in mortality, morbidity, intensive care unit (ICU) admission, LOS, or 30-day readmission were recorded in the groups, but the hospital costs were significantly lower for the LM group (US\$7,441 $\pm 7,897$ vs US $\$ 9,415 \pm 5,515 ; P=0.0028)$. A comparison between the OM and RM groups demonstrated significantly lower morbidity (9.08\% vs $4.02 \% ; P=0.02)$, ICU admission rate $(14.01 \%$ vs $3.36 \% ; P=0.0002)$, and LOS ( $4.42 \pm 5.25$ days vs $2.42 \pm 2.69$ days; $P=0.0001)$ in the RM group. The authors concluded that the perioperative outcomes were superior in the LM and RM groups when compared with OM. Interestingly, the robotic group also had a slight improvement in perioperative outcomes, though this occurred with the price of some increased costs. Moreover, a recent, very comprehensive review $^{23}$ of LM vs RM, including six RCTs (of poor quality) showed similar outcomes for the two methods, and an increased cost for the robotic technique.

Classic laparoscopic fundoplication (LF) has been recognized as the gold standard for surgical treatments of gastroesophageal reflux disease, although a debate still exists on the extent of stomach wrap, specifically, total (Nissen) or partial (Toupet).

Using an American national database, Owen et $\mathrm{al}^{24}$ analyzed a total of 12,079 patients who received fundoplication procedures with the open technique (OF), LF, and robotassisted fundoplication (RLF). No differences in mortality, morbidity, LOS, and ICU cases were detectable. RLF resulted in significantly improved morbidity (5.6\% vs $11 \%$; $P<0.05)$, $\operatorname{LOS}(6.1 \pm 7.2$ days vs $3.0 \pm 3.5$ days; $P<0.05$ ), less ICU admission ( $11.5 \%$ vs $23.1 \% ; P<0.05)$, and interestingly less cost (US $\$ 10,644 \pm 6,041$ vs US $\$ 12,766 \pm 13,982$; $P<0.05)$ compared to $\mathrm{OF}$, although $\mathrm{LF}$ remained superior to RLF, having lower 30-day readmission rate (1.8\% vs 3.6\%; $P<0.05$ ) and cost (US\$7,968 $\pm 6,969$ vs US $\$ 10,644 \pm 6,041$; $P<0.05$ ).

The conclusions were that RLF had similar patient outcomes to LF, with extra costs and higher readmission rate. This may have been due to the retrospective nature of the study, in which the ongoing learning curve for the more recent introduction of robotics could have played a role in justifying the poorer readmission rate.

A meta-analysis ${ }^{25}$ of 221 patients extrapolated by six RCTs, of which 111 underwent LF and 110 underwent RLF, found similar results, with RLF resulting in prolonged total time of surgery, higher costs, and comparable clinical outcomes. 
The gold standard of surgical treatment of esophageal carcinoma is partial or total esophagectomy associated with regional lymphadenectomy, but traditional approaches (three-field McKeown procedure with cervical anastomosis, two-field transthoracic Ivor-Lewis resection and the transhiatal esophagectomy - Orringer procedure) have a high incidence of complication, ranging up to $60 \%$ and comprising mostly of pulmonary complications, leading to increased LOS, costs, and mortality. ${ }^{26,27}$

The minimally invasive esophagectomy (MIE) technique was designed to reduce surgical trauma, resulting in lower mortality and morbidity rates, and all the above mentioned operations are feasible by laparoscopy (thoracoscopy) or hybrid (some step achieved by open matter) techniques, with excellent results. ${ }^{28-30}$ However, MIE is very far from being accepted for routine clinical use worldwide due to the steep learning curve and the unproven cost-effectiveness. ${ }^{31}$ Moreover, several technical variables (laparoscopy, thoracoscopy, combined steps, prone or supine position, stapled or hand-sewn anastomosis), together with the general poor quality of the published studies, has contributed to the confounded outcomes and oncologic results. ${ }^{32}$

Robot-assisted, minimally invasive esophagectomy (RAMIE) facilitates esophageal dissection with enhanced visualization of the three-dimensional fields, allowing the execution of complex maneuvers through the articulated instruments, including lymphadenectomy and visceral anastomoses..$^{33}$

The first cases of RAMIE were described by Giulianotti et al, ${ }^{11}$ Kernstine et al, ${ }^{34}$ and Bodner et $\mathrm{al}^{35}$ in the early 1920 s, but many other surgical approaches have been developed since then.

In 2009, Boone et $\mathrm{al}^{36}$ reported good postoperative data in 47 robotic three-field esophagectomy (mortality 6\%, pulmonary morbidity $44 \%$ ) and oncologically acceptable results demonstrating its feasibility and safety, with comparable outcomes with the open approach. In 2012, Weksler et al ${ }^{37}$ compared the robotic transthoracic procedure with the thoracoscopic approach, and demonstrated the equivalence of the postoperative and oncological data. In 2011, Puntambekar et $\mathrm{al}^{38}$ reported the technical aspects and postoperative data on a series of 32 patients who underwent robotic-assisted esophagectomy with intrathoracic dissection and lymphadenectomy in the prone position. This group demonstrated an incidence of anastomotic leakage (3/32) comparable to the traditional technique, but a lower incidence of pulmonary complications (2/32), which was related to the benefits of the prone position.
However, the recent trend was directed towards a reduction of the three-field McKeown esophagectomy with cervical anastomosis in favor of the two-field Ivor-Lewis esophagectomy due to a high incidence of leaks, recurrent laryngeal nerve injuries, alteration of swallowing, and pharyngeal transit. ${ }^{30,39}$

The robot-assisted Ivor-Lewis esophagectomy (RA-IL) technique was developed later than the three-field approach, and has greater complexity for construction of the chest anastomosis and is mainly performed with a staple device. ${ }^{40,41}$ In a series of 50 patients who underwent RA-IL, de la Fuente et $\mathrm{al}^{42}$ found a postoperative complication rate of $28 \%(15 / 50)$, including one anastomotic leak (2\%), a conduit staple line leak in one patient (2\%), and chyle leak in two patients (4\%). In all cases, they achieved complete resection (R0) and a median number of lymph nodes retrieved of 18.5 .

During MIE, chest esophagogastric anastomosis is performed more frequently with staple devices due to the intrinsic difficulty of performing the procedure, which requires a hand-sewn, video-assisted thoracoscopic suture. However, the articulated instrumentation of the robotic platform can allow these maneuvers with favorable results. Only two papers ${ }^{43,44}$ have reported the feasibility and safety of RAMIE with hand-sewn intrathoracic anastomosis. However, these authors had good postoperative outcomes, without a significant prolonging of the operative time, and no increase of leakage, stenosis, and oncologic failures.

Transhiatal esophagectomy was also carried out robotically, with somewhat higher complications, including $35 \%$ of patients with temporary laryngeal nerve paresis and $25 \%$ of patients with self-limiting cervical leaks. ${ }^{45}$

At present, only very few studies comparing MIE have been published, and none of them have demonstrated real advantages of one method over another. ${ }^{46,47} \mathrm{~A}$ monocentric well-designed trial targeted to robotic MIE started recently. ${ }^{48}$ In one study, the learning curve for RAMIE was found to be at least 20 procedures,${ }^{49}$ and very few centers have sufficient case-load to gain adequate specific proficiency, considering how technically demanding this type of surgery is, even in the traditional open way.

\section{Stomach}

The recognized standard of care for advanced gastric cancer is complete resection (open gastrectomy [OG]) with at least a formal D2-lymphadenectomy, although a debate on the extent of lymphadenectomy has been ongoing for decades. Some less invasive surgery techniques, such as endoscopic 
submucosal dissection and sentinel node mapping, could be appropriate for selected patients with $\mathrm{T} 1$ cancers. ${ }^{31}$

Despite the advancements in recent years in laparoscopy (ie, colorectal surgery), the keyhole approach to gastric surgery is still debated and exclusive to a few skilled surgeons, many of them working in Eastern countries. ${ }^{19,31,50}$ The limits for the widespread use of laparoscopic gastrectomy (LG) are represented mainly by the technical difficulties in both anastomosis, lymphadectomy and conflicting benefits. Nevertheless, two very comprehensive meta-analyses concluded that LG is better or comparable to open surgery with regards to early and long-term outcomes, although at the price of a longer duration of surgery. ${ }^{51,52}$ One rigorous RCT (KLASS trial) confirmed equivalent early outcomes of laparoscopic and open approach to gastrectomy for cancer. ${ }^{53}$

$\mathrm{RS}$ for gastric cancer has been demonstrated to overcome intrinsic limitations of conventional laparoscopic surgery, thanks to the wristed instruments that allow seven degrees of freedom, tremor filtering, three-dimensional vision, and a steady image, thus minimizing blood losses and surgical trauma and improving the surgeon's dexterity when fine manipulation is required. This can be especially helpful during maneuvers in restricted fields and around major vessels, such as in extended lymphadenectomy. ${ }^{54,55}$ Many of these issues could explain the shorter learning curve of robotic gastric surgery compared to laparoscopy. ${ }^{56,57}$

The first experiences of robot-assisted gastrectomy (RAG) were published almost 10 years ago, ${ }^{11,58}$ and more recent papers reported no appreciable differences between patients who had RAG and LG in terms of surgical complications, mortality, conversion rate, LOS, and oncological adequacy. ${ }^{59,60}$ However, only very few meticulous studies have been published on RAG, and a recent meta-analysis ${ }^{61}$ selected only three RCTs comparing robotic surgery and laparoscopy. No significant differences in terms of complications, mortality, conversion, LOS, and number of nodes retrieved were detected between the two groups. A more inclusive meta-analysis ${ }^{62}$ reached the same conclusions, with some trends of better perioperative outcome with RAG.

In their series of 5,839 patients $(4,542 \mathrm{OG}, 861 \mathrm{LG}$, and 436 RAG), Kim et $\mathrm{al}^{63}$ found that the overall rates of complications, reoperation, and mortality were similar between the three groups. Postoperative ileus and intestinal obstruction, as well as intra-abdominal fluid collections and abscesses, occurred more frequently after open surgery, while anastomotic leakage was low, but significantly more common, after the minimally invasive approach (LG 2.1\%, RAG 2.3\%, OG $1.1 \% ; P=0 \cdot 017)$. The authors hypothesized that the higher rate of leaks in LG and RAG may be associated with the limited tactile feedback or differences in staple-line reinforcement, which is not performed in laparoscopic and robotic procedures. However, the learning curve and the possibility of uncorrected bowel rotation in a small surgical field could also have contributed to the observed differences.

D2-lymphadenectomy in RAG is easier than in laparoscopy, and seems to be as accurate as in open surgery, with the possibility of allowing the surgeon to perform enlarged resections and more complex reconstructions (ie, hand-sewn esophagojejunostomy after total gastrectomy or Roux-en-Y jejunojejunostomy)..$^{57,64-66}$ Nevertheless, it has been reported in several studies that digestive restoration was performed extracorporeally through the same mini laparotomy used for specimen removal. ${ }^{59,67}$ This hybrid-open technique was used both in gastrojejunostomy and gastroduodenostomy following distal gastrectomy, as well as in esophagojejunostomy following total gastrectomy, but had less reproducible results in Western patients with higher fat mass.

Other studies have reported the following similar results in terms of postoperative outcomes after RAG compared to LG: few differences were found in the time required for mobilization, passed flatus, and resumption of diet. ${ }^{68}$ The LOS was shorter in patients undergoing RAG than in those having LG, but this difference was not found to be statistically significant in two meta-analyses. ${ }^{59,61}$ However, the hospital stay for RAG was significantly shorter than that for OG and was consistent in all series. ${ }^{59}$

The mean operating time is commonly longer in $\mathrm{RS}$ than in conventional laparoscopy or open surgery. ${ }^{59,67}$ However, in one series that excluded the initial learning curve, the authors reported a similar operating time (234 minutes versus 220 minutes). ${ }^{69}$ Obviously, all the robotic procedures needed additional setup procedures, including docking, which often requires less than 30 minutes. ${ }^{59,70}$ Both setup time and operative time, together with the delay caused by instrument changes, are expected to decrease as the experience of the surgical and nursing teams increases. ${ }^{11,64,69-71}$

In comparative studies among $\mathrm{OG}, \mathrm{LG}$, and RAG, some authors $^{63,72}$ have reported that the estimated blood loss in the robotic group was significantly lower than in the open and laparoscopic groups. Similar results were confirmed in the meta-analysis from Xiong et al, ${ }^{61}$ whose data appear to confirm the ability of surgeons to better control bleeding when using the robotic system, compared to conventional laparoscopy.

When considering the cornerstone of oncological adequacy, most authors have reported a mean number of 
nodes higher than 30, which is in line with the recommended standard for conventional open D2-lymphadenectomy. ${ }^{60,71,72}$ In a recent meta-analysis including a total of 7,200 patients (663 RAG, 1,236 LG, 5,301 OG), Hyun et al ${ }^{59}$ reported a statistical equivalence in the number of nodes when comparing the three approaches, even when a matched analysis for the extent of lymphadenectomy and the type of gastrectomy was carried out. Likewise, in the meta-analysis from Xiong et $\mathrm{al},{ }^{61}$ there were no differences observed in the number of nodes retrieved between the RAG and LG procedures.

The majority of studies reported free resection margins at pathological examination in $100 \%$ of cases following RAG, ${ }^{64,67}$ which likely reflects some preoperative selection bias towards patients with early-stage disease.

Although data on long-term outcomes and survival after RAG are still lacking, a paper published by Pugliese et al, ${ }^{70}$ with a mean observation length of 53 months, reported no differences in 5-year survival between LG and RAG.

Interestingly, some authors have reported that all histologically proven $\mathrm{N}+$ patients who underwent RAG started adjuvant treatment without any surgery-related delay within 30 days after surgery. ${ }^{64}$

According to the majority of experiences reported in the literature, RAG with limited lymphadenectomy could be indicated for cancers at the initial stages (if the patients are not eligible for endoscopic resections), while RAG with D2-lymphadenectomy is indicated for the treatment of more advanced neoplasms. However, the specific exclusion criteria for RS, as is the case for laparoscopic surgery, include intolerance to pneumoperitoneum, T4 cancers, or the presence of distant metastases. ${ }^{61,73}$

\section{Liver, gallbladder, and biliary tract}

Although the first laparoscopic liver resection was reported by Reich et $\mathrm{al}^{74}$ in 1991, the minimally invasive laparoscopic approach to hepatic resection had long been underestimated due to the complexity of the vascular and biliary anatomy of the liver, the exposure difficulties, and propensity for bleeding during indirect manipulation.

However, laparoscopic liver resections have also become possible with the availability of new instruments that allow a relatively bloodless liver transection. The feasibility and safety of laparoscopic liver resections have been demonstrated by several recent studies, including a few comparative trials, providing some evidence to support the further development of this technique. ${ }^{75-79}$

The advantages of minimally invasive surgery are wellknown. These include shorter LOS, decreased postoperative pain, rapid return to preoperative activity, improved cosmesis, and decreased postoperative ileus, together with a reduction in ascites formation in cirrhotic patients. ${ }^{76}$

According to an international consensus report, the best candidates for laparoscopic liver resection include only those with a surface solitary lesion of less than $5 \mathrm{~cm}$ (despite for malignancy) that can be removed by limited resection or left lateral sectionectomy. ${ }^{80,81}$ Otherwise, laparoscopic major or complex hepatectomies, often including the resection of the right posterior-superior segments, have been performed selectively and mostly in specialized centers because of the intrinsic technical limitations of laparoscopy that can only be partially surpassed by the ability of the individual surgeon and/or extensive training. ${ }^{80,82}$

Although some large (300 patients, 103 cancerous) single-center, case-matched experiences ${ }^{83}$ have concluded that mini-invasive hepatectomy (including major resections) compared favorably with contemporaneous open controls in terms of perioperative outcomes and oncological adequacy, a Cochrane review by Rao and $\mathrm{Ahmed}^{84}$ reported that due to the poor quality of the scientific reports, no definitive conclusion can be drawn on the benefits or harm of laparoscopy.

As is the case for other major operations, robotics could play a role in overcoming some problems prior to the popular application of minimally invasive surgery for liver resection. For example, the robotic interface is able to help the surgeon during dissection in deep and narrow spaces and for the knottying of vascular structures. The use of robotic instruments can also resolve some life-threatening situations, such as a caval injury caused by a stapler malfunction. ${ }^{85}$

The indications for robotic hepatic resection range from benign or malignant lesions (hepatocellular carcinoma [HCC] and colorectal metastasis [CRM], and gallbladder cancer $)^{86-88}$ to living donor hepatectomy for transplant. ${ }^{89}$ Previously, there was a tendency to resect benign lesions, but with increasing experience, at present, the majority of indications are for malignancies, ${ }^{90-94}$ and amount to a few hundred cases worldwide. ${ }^{88,95}$

Nevertheless, the segment location of the lesion plays a more important role in the surgical decision, rather than the nature of the lesion itself. Every liver segment has been approached robotically, including the posterior segments, ${ }^{96}$ and major hepatectomy is also amenable in this manner. ${ }^{90,93,97,98}$ The robotic platform can lead to an easier exposition of posterior segments through a stable surgical field and view, the use of a flexible sonographic probe, and the Endowrist instruments. 
The cornerstones of robotic liver surgery are represented by careful laparoscopic ultrasonographic assessment (available also as a dedicated probe with a picture-in-picture imaging in the console), control of the pedicles, and a slowsafe parenchymal transection.

Many transectional techniques are amenable to robotic employment, including those using a harmonic device, ${ }^{90,96,98,99}$ an ultrasonic aspirator, ${ }^{98,99}$ bipolar forceps,${ }^{90,96}$ electrocautery ${ }^{99}$ or fracture technique using robotic Maryland forceps. ${ }^{100}$ Large veins and major pedicles were divided with the use of a stapler, and typically, the vascular and biliary elements were divided or by robot with clips and/or suture ligation, or by the assistant using a harmonic scalpel, clips, or scissor.

In two comparative studies, Berber et a ${ }^{100}$ found no differences in the mean operation times of the robotic and laparoscopic procedures, whereas a cohort-matched study conducted by $\mathrm{Ji}$ et $\mathrm{a}^{101}$ and a retrospective study conducted by Spampinato et a ${ }^{102}$ suggested that the robotic procedure required longer operation times than laparoscopic and open resection surgeries. The mean intraoperative blood loss ranged $50-660 \mathrm{~mL}$.

Three recent papers that conducted matched comparisons of robotic and laparoscopic liver resections (globally, 203 laparoscopic vs 129 robotics) failed to show significant differences between the two techniques. ${ }^{94,103,104}$ However, the robotics technique could have facilitated the management of lesions arising from the posterior segments, thus increasing the number of patients undergoing minimally invasive resection (from 2 to 10 times) and major hepatectomies. Long-term outcomes, larger patient records, and comparative studies (with open surgery and pure laparoscopy) are not yet available.

The gallbladder is approachable in the classical way by the robotic interface, with excellent results, ${ }^{105}$ or by using a single incision. ${ }^{106}$ Moreover, near infrared technology (Firefly) can be of great help in the visualization of biliary anatomy ${ }^{107}$ However, the cost-effectiveness of robotic cholecystectomy makes its routine use highly questionable.

\section{Pancreas}

Major pancreatic surgery (pancreaticoduodenectomy, total pancreatectomy, and distal pancreatic resection) is known to be a challenge for the surgeon due to complex reconstructions and the high incidence of postoperative complications. Simpler enucleations for neuroendocrine or benign disease could also lead to the development of life-threatening fistulas or pancreatitis.
From a theoretical point of view, any effort to be less invasive would be of enormous benefit for the patients. A very original and interesting survey carried out on patients and medical personnel found a trend of preference towards laparoscopic procedures when dealing with pancreatic benign disease and towards open surgery in cases of cancer. ${ }^{108}$

Conversely, the intrinsic difficulties, the questionable benefits, and the relatively low incidence of pancreatic cancer, which limits the gaining of sufficient skills, have confined the use of laparoscopic pancreatic surgery to a few specialized centers. ${ }^{109}$ For example, less than $5 \%$ of hepatobiliopancreatic procedures in a large, nationwide American database were performed by a mini-invasive approach. ${ }^{110}$

However, while laparoscopic distal left pancreatectomy (LDP) has reached a sufficient level of standardization, especially for benign or neuroendocrine diseases, ${ }^{111-115}$ laparoscopic pancreatoduodenectomies (LPD), although feasible, remain confined to anecdotal experiences carried out by extremely skilled surgeons. ${ }^{116-119}$ A 2014 review with very rigorous and statistical inclusion criteria, in which only six trials met the requirements, collected no more than 169 pancreatoduodenectomies carried out worldwide by a mini-invasive approach (laparoscopic or robotic). ${ }^{120}$ Another more inclusive recent review ${ }^{121}$ that assessed 638 patients who were operated on robotically or laparoscopically, or by the open approach, reported a reduced LOS and blood loss at the price of longer operative time and no difference in the incidence of fistulas. It is interesting to note that the most important review had to pool robotic cases with pure laparoscopic operations in order to reach a sufficient level of statistical power.

Similar to other complex gastrointestinal procedures, RS could help overcome many of the challenging steps of the laparoscopic approach, including biliary and pancreatic anastomosis or the preservation of the spleen. ${ }^{122-126}$ Some surgeons ${ }^{127-129}$ have reported more than excellent results with robotic-assisted pancreatectomies compared to the open approach. For this reason, the conversion rate seems to be lowered by robotic assistance compared to pure laparoscopy $\left(0 \%-18.3 \%^{126,130-132}\right.$ vs $\left.0 \%-46 \%{ }^{133,134}\right)$, which represents the index of better technical standardization, and the possibility of managing bleeding, challenging dissections, and any other intraoperative trouble.

One of the first large statistical studies was that published by Giulianotti et a ${ }^{122}$ in 2010, with 134 robot-assisted pancreatic operations, including robot-assisted PD (RPD) in 60 patients. Conversion, morbidity, and mortality rates for the whole series were $10.4 \%, 26 \%$, and $2.2 \%$, respectively. 
The rate of pancreatic fistula was $31.3 \%$ for PD and 20.9\% after distal pancreatectomy. Only one patient was reoperated on.

Similarly, a more recent single-surgeon experience ${ }^{131}$ reported 34 patients (representing only $14 \%$ of the total pancreatoduodenectomies carried out in the same period due to careful exclusion of complex or obese patients) operated on by RPD with a mean duration of surgery of 597 minutes and an extra cost of more than $€ 6,000$. On the other hand, the patients' oncologic parameters (harvested nodes, margins) and perioperative results were good ( $0 \% 30$-day mortality and global 55\% morbidity).

The largest series was that published by Zureikat et al ${ }^{130}$ from the University of Pittsburg, which included 250 robotic pancreatic resections. Of these, 132 were RPD and 83 were robotic distal pancreatectomy (RDP), while the remaining were atypical resections, enucleations, or total pancreatectomies. The postoperative complications were recorded for 90 days. The crucial endpoints were a 30 - and 90-day mortality of $0.8 \%$ and $2.0 \%$, respectively, Clavien 3 and 4 complication rates of $14 \%$ and $6 \%$, and the International Study Group on Pancreatic Fistula grade C fistula rate of $4 \%$. The mean operative time for the two most common procedures was 529 minutes for RPD and 257 minutes for RDP.

A meta-analysis by Zhang et al, ${ }^{135}$ which included seven trials, suggested that robotic pancreatectomy is as safe and efficient as, if not superior to, open surgery, although the evidence was highly insufficient. The pooled analysis compared 137 robotic and 203 open pancreatectomies, and found superior results in morbidity, redo surgery, and resection margins in the robotic group. Blood loss and LOS were also lower in the robotic group, although these differences were not statistically significant. Conversely, operating time was significantly shorter in the open group. No differences in fistula and mortality rates were evident.

Another very accurate meta-analysis ${ }^{136}$ reported comparable results of RPD and LPD or open pancreatoduodenectomies (OPD) in terms of morbidity and mortality. However, the limits of the studies included were several and important. For example, no cost-effectiveness analysis was carried out, the techniques applied were heterogeneous, and the case series were biased by patient selection. A specific study targeted for the comparison of robotic and open total pancreatectomy reported that the former was associated with a longer mean operative time (600 minutes vs 469 minutes; $P=0.014$ ) but decreased mean blood loss (220 vs $705 \mathrm{ml} ; P=0.004) .{ }^{132}$
However, all these feasibility experiences represent the baseline safety profile of the techniques and should encourage the development of more rigorous trials.

In our opinion, full LPD should be abandoned in favor of the development of robotically assisted operations, with a careful comparison of the outcomes with respect to open surgery only. Early results for major pancreatic surgery appear encouraging when considering feasibility, safety, and oncological outcomes. Undoubtedly, the dexterities acquired by the use of the robotic interface could most likely extend the spectrum of the mini-invasive approach to include advanced pancreatic cancer and vascular reconstructions.

This concept is most likely less radical when considering LDP, but in cases of spleen preservation or radical dissections for cancer, the robotic option should be taken into consideration, ${ }^{137-140}$ as it has a reported success rate of more than $95 \% .{ }^{135,141}$

\section{Colon and rectum}

Currently, the surgical treatment of both colorectal benign diseases and malignancies has been recognized to be achievable by the laparoscopic route. ${ }^{19,142,143}$ Laparoscopic colorectal surgery has gained widespread application worldwide, due to the impressive number of statistically robust studies that have been published, including many RCTs ${ }^{14-148}$ with long follow-up ${ }^{149-153}$ and meta-analyses. ${ }^{154-156}$

Other reasons for the larger penetration of laparoscopic colorectal surgery, compared to upper gastrointestinal and hepatopancreatic surgery, is represented by the high incidence of colorectal cancer, which permits adequate case-load with acceptable technical challenge in most of the hospitals worldwide.

On the other hand, data supporting routine laparoscopic rectal surgery is more difficult to validate. This is because the famous CLASSIC trial ${ }^{147}$ reported inferior results without oncologic safety and a Cochrane review ${ }^{157}$ did not assess the safety of the procedure compared to open surgery. The narrow experience of many of the surgeons participating in the initial trials could also have played a role in justifying the poor results.

However, some more recent RCTs, ${ }^{158}$ targeted at the laparoscopic treatment of rectal cancer, have had good results in terms of oncologic safety, while others ${ }^{159,160}$ have reported superior perioperative outcomes with respect to standard open rectal resection. A meta-analysis ${ }^{161}$ confirmed the superiority of laparoscopic rectal resection with total mesorectal excision (TME) in the early- and medium-term period. 
Surprisingly, the percentage of laparoscopic colectomies performed in many hospitals remains low because it requires a longer learning curve and a need for extensive training of surgeons. ${ }^{162,163}$ The application of RS could resolve and reduce the learning curve problem for colonic resections although rectal resections for cancer remain challenging procedures for the novice robotic surgeon. ${ }^{164-166}$

The first robot-assisted colon resection using the da Vinci Surgical System was described by Weber et $\mathrm{al}^{167}$ in 2001, and some surgeons have begun to perform robotic colorectal surgery (RCRS) routinely, ${ }^{168-170}$ although according to a large recent American database, the percentage of robotic operations remained less than $3 \% .{ }^{171}$ The same retrospective database analysis failed to confirm the benefits of RCRS over conventional laparoscopy, except for decreased conversion rates, with a higher rate of bleeding and increased costs observed. ${ }^{171}$

Right hemicolectomy has been proposed as a first step for approaching RCRS in order to reduce the learning curve for more challenging procedures, such as robotic rectal resections (RRR). ${ }^{166,172-174}$ However, the real advantages of right robotic hemicolectomy (RRH) towards the standard laparoscopic approach are less evident compared to rectal resection.

Many studies comparing laparoscopic and RRH have demonstrated that the robotic procedure is longer and more expensive, with no significant differences in the surgical clearance, morbidity, LOS, and oncological outcomes. ${ }^{175-177}$

D'Annibale et $\mathrm{al}^{178}$ reported the safety and technical feasibility of RRH, with better lymph node sampling when compared to standard laparoscopy, while Bianchi et al ${ }^{179}$ stressed the advantages of the robotic da Vinci system when performing a complete mesocolic excision with a high ligation of the vessels, in order to obtain the highest number of lymph nodes retrieved. In addition, the same author underlined the benefit of the robot during the anastomotic step that is hand-sewed intracorporeally.

Left hemicolectomy and sigmoidectomy with the da Vinci Robotic system are still associated with longer operative times and higher costs, as compared to laparoscopy. ${ }^{180}$ However, it is likely that the robot could have a place in resolving some complex situations, such as lymph node dissection around the major vessels and the necessity of intracorporeal anastomosis. ${ }^{181}$ Other good indications for robotic colectomy are diverticulitis with fistulae, concomitant liver resections, multivisceral resections for T4 tumors, and morbidly obese patients or patients prone to bleeding for hematologic diseases. Nevertheless, the short-term oncological outcomes are similar, ${ }^{180,181}$ if not superior, ${ }^{182}$ to the laparoscopic approach. A small RCT comparing robotic and laparoscopic left colectomies resulted in similar clinical results. ${ }^{183}$ Many centers have introduced the use of robots to perform RRR to reduce the difficulties of performing a formal laparoscopic TME; ${ }^{184} \mathrm{RRR}$ is recognized as one of the best applications of RS. ${ }^{182,185,186}$

At least two different techniques to approach rectal cancer exist in the literature. ${ }^{187}$ One involves a combination of laparoscopic (mobilization of the left colon) and robotic (pelvic dissection and TME) approaches, and this hybrid approach results in a shorter operative time. ${ }^{188-191}$ The other technique is achieved solely by the use of the robotic technique, although through a so-called 'single docking' ${ }^{192-195}$ or 'dual docking' ${ }^{196}$ system.

TME carried out via the laparoscopic and robotic approaches have been compared in some nonrandomized trials, with a superior outcome for the robotic procedure in terms of nerve sparing and number of lymph nodes retrieved. ${ }^{197,198}$ Other studies concluded that the quality of TME carried out robotically was encouraging, if not superior, to that achieved by traditional laparoscopy, in terms of prevention of sexual and urinary dysfunction, and intraoperative blood loss. ${ }^{199,200}$

When considering locoregional recurrences, the distance of recurrences, and total recurrences occurring, Kwak et al ${ }^{201}$ did not find any significant difference between the two approaches. Moreover, Kang et $\mathrm{al}^{202}$ reported no significant differences in 2-year survival following robotic, laparoscopic, and open group rectal surgeries.

Unsurprisingly, RRR is more expensive than laparoscopy $^{203}$ and is most likely equivalent in terms of short-term results. ${ }^{204}$ Nevertheless, the good oncologic parameters (harvested nodes, margins, and recurrence) yielded following the robotic techniques has led to the consideration of RRR as safe. ${ }^{191,205} \mathrm{~A}$ prospective, international, multicenter RCT to test robotic versus standard rectal resection is still ongoing. ${ }^{206}$

Only a few papers have assessed the learning curve for RRR. Specifically, Pigazzi et a $\mathrm{l}^{207}$ reported how operative time decreased after 20 consecutive procedures, while D'Annibale et al ${ }^{208}$ obtained a decrease in mean operative time from 312.5 minutes in the first 25 procedures to 238.2 minutes in the last ten $(P=0.002)$.

Another important issue for the development of RRR is the lower conversion rates with respect to laparoscopic 
rectal resection, ${ }^{209}$ which could lead to some reduction of global hospital costs during the learning curve, and an easier approach to ultra-low resections and lateral pelvic dissection in selected cases.

Lastly, the da Vinci platform was introduced to overcome the technical limitations of transanal endoscopic microsurgery (TEM). ${ }^{210}$ The articulating instruments could effectively be used during a full-thickness transanal resection of a rectal polyp or neoplasm. ${ }^{211,212}$ However, larger case series and trials are needed to validate the technique and to compare the outcomes with respect to the classical approach.

\section{Miscellaneous gastrointestinal procedures}

Many other gastrointestinal procedures have been carried out by robotic approaches, including pouch reconstruction after radical cystectomy, ${ }^{213}$ small bowel resections, and inflammatory bowel disease surgery. ${ }^{214}$ However, most of them still remain anecdotal experiences managed by very skilled robotic surgeons. ${ }^{11}$

Nevertheless, some interesting experiences with good results have been published regarding robotic bariatric surgery and sacrocolpopexy. For example, the application of the da Vinci ${ }^{\circledR}$ System during Roux-en-Y gastric bypass for morbid obesity was safe and feasible, with a reduction of the operating room time ( 130 minutes vs 149 minutes; $P=0.02$ ) in patients with higher body mass index and hand-sewed anastomosis. ${ }^{215}$ Additionally, a recent review ${ }^{216}$ article including 22 articles of poor quality and characterized by gross heterogeneity of techniques was conducted. Despite the use of the robot, most of the surgeons finished the bariatric procedures (biliopancreatic diversion, Roux-en-Y gastric bypass, and sleeve gastrectomy) with stapled anastomosis. The authors concluded that no evidence supported the use of the robot for more complex cases. Another review ${ }^{217}$ reported comparable results between laparoscopic and robotic Roux-en-Y gastric bypass, but with higher costs associated with the latter.

One of the very few RCTs available in the literature regarding the use of the da $\mathrm{Vinci}^{\circledR}$ System was that conducted on sacrocolpopexy, ${ }^{218}$ in which 78 women were treated randomly by robotic or laparoscopic approaches. The total operative time was significantly longer in the robotic group (67-minute difference; 95\% confidence interval: 43-89 minutes; $P<0.001$ ), with the extra time persisting even when separating the anesthesia time, whole surgical time, and suturing. Patients in the robotic group also experienced higher pain after surgery. Unsurprisingly, the costs were greater with the robot (mean difference USD1,936). However, the two groups had significant improvement in vaginal support and functional outcomes at 1 year after surgery. Similar results were reported in another recent $\mathrm{RCT},{ }^{219}$ although the difference in costs disappeared when excluding the purchase and maintenance of the system.

\section{Discussion}

The introduction of minimally invasive techniques has transformed surgery in the past three decades. Patient benefits from mini-invasive surgery include less operative blood loss, less postoperative pain and consequently, reduced requirement of narcotics, and a shorter LOS. The better integration of minimally invasive surgery with neoadjuvant and adjuvant multimodal therapies represents another strong element.

Laparoscopy is now accepted and is most likely recognized as the gold standard in the management of some gastrointestinal procedures (ie, colonic surgery). However, our opinion is that greater development should be expected for robotics when dealing with esophageal, gastric, rectal, hepatic, and pancreatic surgery (Table 1). Moreover, robotic technology could lead to a crucial improvement of laparoendoscopic, single-site surgery, which currently requires excellent surgical skills and dexterity. ${ }^{220}$

The potential capabilities of new robotic technologies, including three-dimensional viewing, intraoperative guidance, training simulators, and robotics, will undoubtedly contribute to improving minimally invasive surgery.

Table I State of the art: the feasible approaches to gastrointestinal disease and the authors' opinions regarding future developments

\begin{tabular}{llll}
\hline District & $\begin{array}{l}\text { Open } \\
\text { surgery }\end{array}$ & $\begin{array}{l}\text { Laparoscopic } \\
\text { surgery }\end{array}$ & Robotic \\
\hline Esophagus & + & ++ & +++ \\
Reflux disease & - & ++ & +++ \\
Stomach (proximal) & + & + & ++ \\
Stomach (distal) & + & ++ & +++ \\
Liver (major resection) & + & - & ++ \\
Liver (minor resection) & + & ++ & + \\
Liver (posterolateral & + & - & ++ \\
segments) & & & + \\
Gallbladder & - & ++ & ++ \\
Biliary tree & + & ++ & ++ \\
Pancreas (head) & + & - & ++ \\
Pancreas (body-tail) & + & ++ & +++ \\
Pancreas (body-tail & + & ++ & + \\
spleen preserving) & & & ++ \\
Small bowel & + & + & ++ \\
Colon & - & ++ & + \\
Rectum & - & & + \\
\hline Note: Currenty, & & $+5 y$ & + \\
\hline
\end{tabular}

Note: Currently, open surgery is considered the standard and has a + by default, except in cases of colorectal surgery, reflux disease, and cholecystectomy. 
Wristed instruments offering seven degrees of freedom, tremor filtering, scaled motion, stereoscopic steady view with excellent high definition, optimal working ergonomics, and avoidance of the 'fulcrum effect' are the main strengths of the da Vinci surgical system. ${ }^{207,221}$

Moreover, new devices, such as fluorescence in situ, picture-in-picture technology, navigation surgery through virtual reality software, ${ }^{222}$ and EndoWrist manipulation adapted to sealing devices could increase the advantages of robotic procedures, even for pure laparoscopy. For example, indocyanine green and fluorescence imaging are currently applied for ureter localization, node mapping, biliary anatomy, and bowel vitality appraisal. ${ }^{223-226}$

Conversely, other robotic applications, such as telesurgery, which were considered highly appealing by the mass media, are very far from becoming widely applied. ${ }^{227}$

The flexibility of surgical manipulation is very important and convenient during tissue dissection, suturing, and reconstruction. The instruments used in traditional laparoscopic surgery do not have much flexibility when they are applied into the abdominal cavity. Robotic surgical systems have recently been introduced to enhance a surgeon's dexterity in the surgical field. In particular, the robot has been shown to improve nondominant hand performance ${ }^{228,229}$ and reduce the need for extensive preemptive training in laparoscopic techniques. ${ }^{56}$

The major technical advantages of robot-assisted gastrointestinal surgery are appreciated during lymph node dissection, intracorporeal reconstruction, enlarged resections, and complex reconstructions. The better detection of vessels due to the greater field of view and the high precision of bleeding control can account for decreased blood loss in RS. The learning curve and reproducibility of RAS seem to be shorter and more feasible than with conventional laparoscopy. As such, robotics has the potential to contribute to the standardization and widespread application of minimally invasive surgery for the treatment of gastric cancer, making it a routine approach even in patients with advanced stages of disease.

Undoubtedly, the widespread adoption of robotic technology in gastrointestinal and other surgeries is far from becoming a reality at the present time. The three main drawbacks of RS are represented by the increased costs, longer operative times, and unproven benefits for patients. ${ }^{7}$ The cost associated with RS was found to be higher than both the open and laparoscopic approaches..$^{9}$ This is the main limitation of RS and will be a major obstacle that needs to be overcome before widespread acceptance occurs.
Conversely, robotic technology is rapidly changing, and the many continuous technical improvements will most likely lead to some reduction in its intrinsic defects. For example, an increase in the number of market competitors will reduce the initial costs, while the mechanical developments may reduce the weight, encumbrance, and spatial limitations of the arms. On the other hand, the increased experience of each single center will lead to an increase of the total number of procedures performed yearly, thus reducing the dynamic costs for each single operation.

However, the longer operative time has many 'not surgical' explanations. Firstly, the setting up of the theater and the docking of the robot contributes to the total time. Secondly, the delay in changes in the instruments also plays a role. These two time delays are expected to decrease after a minimum of gained experience. However, it is of crucial importance that the development of a full robotic program should follow the important principles of safety and nonmaleficence, in order to guarantee the maximum safety of each patient during the learning curve..$^{20}$

Nevertheless, only a few selected tertiary centers with the greatest surgical experience in both laparoscopy and surgical oncology have the adequate background and prerequisites for addressing the learning curve safely, although none should forego careful tutoring, monitoring, and validation of the data obtained. In order for this to happen, robotic technology needs to prove itself as significantly advantageous and the costs associated with its use will need to decrease. Multicenter, randomized, controlled trials and long-term follow-up evaluations are needed to definitively establish the oncological adequacy of RAS.

\section{Conclusion}

Robotics offers many potential technical advantages over conventional laparoscopy, including three-dimensional highdefinition steady viewing, intraoperative guidance, training simulators, the use of wristed instruments with seven degrees of freedom, tremor filtration, scaled motion, and avoidance of the 'fulcrum effect'. Robotics will most likely lead to the full applicability of minimally invasive surgery benefits to the most complex surgical procedures, reducing the learning curves.

However, the widespread adoption of robotic technology in gastrointestinal and other surgeries is far from becoming a reality. The three main drawbacks of RS are represented by the increased costs, the longer operative times, and unproven benefits for patients. Most of these concerns are expected to be resolved with future studies and gaining of experience. 


\section{Disclosure}

The authors declare no conflicts of interest in this work.

\section{References}

1. Ng AT, Tam PC. Current status of robot-assisted surgery. Hong Kong Med J. 2014;20(3):241-250.

2. Chang SL, Kibel AS, Brooks JD, Chung BI. The impact of robotic surgery on the surgical management of prostate cancer in the United States. BJU Int. Epub June 23, 2014.

3. US Food and Drug Administration, July 2000 510(k) Clearances. Available at: http://www.accessdata.fda.gov/scripts/cdrh/cfdocs/cfpmn/ pmn.cfm?ID=K990144. Accessed December 27, 2014.

4. Anderson JE, Chang DC, Parsons JK, Talamini MA. The first national examination of outcomes and trends in robotic surgery in the United States. J Am Coll Surg. 2012;215(1):107-114; discussion 114-116.

5. Benmessaoud C, Kharrazi H, MacDorman KF. Facilitators and barriers to adopting robotic-assisted surgery: contextualizing the unified theory of acceptance and use of technology. PLoS One. 2011;6(1):e16395.

6. Lee JR. Anesthetic considerations for robotic surgery. Korean $J$ Anesthesiol. 2014;66(1):3-11.

7. Turchetti G, Palla I, Pierotti F, Cuschieri A. Economic evaluation of da Vinci-assisted robotic surgery: a systematic review. Surg Endosc. 2012;26(3):598-606.

8. Garas G, Ibrahim A, Ashrafian H, et al. Evidence-based surgery: barriers, solutions, and the role of evidence synthesis. World J Surg. 2012;36(8):1723-1731.

9. Barbash GI, Glied SA. New technology and health care costs - the case of robot-assisted surgery. $N$ Engl J Med. 2010;363(8):701-704.

10. Tsui C, Klein R, Garabrant M. Minimally invasive surgery: national trends in adoption and future directions for hospital strategy. Surg Endosc. 2013;27(7):2253-2257.

11. Giulianotti PC, Coratti A, Angelini M, et al. Robotics in general surgery: personal experience in a large community hospital. Arch Surg. 2003;138(7):777-784.

12. Buchs NC, Addeo P, Bianco FM, et al. Perioperative risk assessment in robotic general surgery: lessons learned from 884 cases at a single institution. Arch Surg. 2012;147(8):701-708.

13. Liberman D, Trinh QD, Jeldres C, Zorn KC. Is robotic surgery costeffective: yes. Curr Opin Urol. 2012;22(1):61-65.

14. Salman M, Bell T, Martin J, Bhuva K, Grim R, Ahuja V. Use, cost, complications, and mortality of robotic versus nonrobotic general surgery procedures based on a nationwide database. Am Surg. 2013;79(6): $553-560$.

15. Gutt CN, Oniu T, Mehrabi A, Kashfi A, Schemmer P, Büchler MW. Robotassisted abdominal surgery. Br J Surg. 2004;91(11):1390-1397.

16. Fernandes E, Elli E, Giulianotti P. The role of the dual console in robotic surgical training. Surgery. 2014;155(1):1-4.

17. Broeders IA. Robotics: The next step? Best Pract Res Clin Gastroenterol. 2014;28(1):225-232.

18. Mohammadzadeh N, Safdari R. Robotic surgery in cancer care: opportunities and challenges. Asian Pac J Cancer Prev. 2014;15(3): 1081-1083.

19. Bencini L, Bernini M, Farsi M. Laparoscopic approach to gastrointestinal malignancies: toward the future with caution. World J Gastroenterol. 2014;20(7):1777-1789.

20. Larson JA, Johnson MH, Bhayani SB. Application of surgical safety standards to robotic surgery: five principles of ethics for nonmaleficence. J Am Coll Surg. 2014;218(2):290-293.

21. Hanna JM, Onaitis MW. Robotic benign esophageal procedures. Thorac Surg Clin. 2014;24(2):223-229, vii.

22. Shaligram A, Unnirevi J, Simorov A, Kothari VM, Oleynikov D. How does the robot affect outcomes? A retrospective review of open, laparoscopic, and robotic Heller myotomy for achalasia. Surg Endosc. 2012;26(4):1047-1050.
23. Falkenback D, Lehane CW, Lord RV. Robot-assisted oesophageal and gastric surgery for benign disease: antireflux operations and Heller's myotomy. ANZ J Surg. Epub July 9, 2014.

24. Owen B, Simorov A, Siref A, Shostrom V, Oleynikov D. How does robotic anti-reflux surgery compare with traditional open and laparoscopic techniques: a cost and outcomes analysis. Surg Endosc. 2014;28(5):1686-1690.

25. Wang Z, Zheng Q, Jin Z. Meta-analysis of robot-assisted versus conventional laparoscopic Nissen fundoplication for gastro-oesophageal reflux disease. ANZ J Surg. 2012;82(3):112-117.

26. McCulloch P, Ward J, Tekkis PP, et al. Mortality and morbidity in gastro-oesophageal cancer surgery: initial results of ASCOT multicentre prospective cohort study. BMJ. 2003;327(7425):1192-1197.

27. Low DE, Bodnar A. Update on clinical impact, documentation, and management of complications associated with esophagectomy. Thorac Surg Clin. 2013;23(4):535-550.

28. Biere SS, van Berge Henegouwen MI, Maas KW, et al. Minimally invasive versus open oesophagectomy for patients with oesophageal cancer: a multicentre, open-label, randomised controlled trial. Lancet. 2012;379(9829):1887-1892.

29. Kinjo Y, Kurita N, Nakamura F, et al. Effectiveness of combined thoracoscopic-laparoscopic esophagectomy: comparison of postoperative complications and midterm oncological outcomes in patients with esophageal cancer. Surg Endosc. 2012;26(2):381-390.

30. Luketich JD, Pennathur A, Awais O, et al. Outcomes after minimally invasive esophagectomy: review of over 1000 patients. Ann Surg. 2012;256(1):95-103.

31. Goldfarb M, Brower S, Schwaitzberg SD. Minimally invasive surgery and cancer: controversies part 1. Surg Endosc. 2010;24(2):304-334.

32. Uttley L, Campbell F, Rhodes M, Cantrell A, Stegenga H, Lloyd-Jones M. Minimally invasive oesophagectomy versus open surgery: is there an advantage? Surg Endosc.3 2013;27(11):724-731.

33. Lehenbauer D, Kernstine KH. Robotic esophagectomy: modified McKeown approach. Thorac Surg Clin. 2014;24(2):203-209.

34. Kernstine KH, DeArmond DT, Karimi M, et al. The robotic, 2-stage, 3 -field esophagolymphadenectomy. J Thorac Cardiovasc Surg. 2004;127(6):1847-1849.

35. Bodner JC, Zitt M, Ott H, et al. Robotic-assisted thoracoscopic surgery (RATS) for benign and malignant esophageal tumors. Ann Thorac Surg. 2005;80(4):1202-1206.

36. Boone J, Schipper ME, Moojen WA, Borel Rinkes IH, Cromheecke GJ, van Hillegersberg R. Robot-assisted thoracoscopic oesophagectomy for cancer. Br J Surg. 2009;96(8):878-886.

37. Weksler B, Sharma P, Moudgill N, Chojnacki KA, Rosato EL. Robot-assisted minimally invasive esophagectomy is equivalent to thoracoscopic minimally invasive esophagectomy. Dis Esophagus. 2012;25(5):403-409.

38. Puntambekar SP, Rayate N, Joshi S, Agarwal G. Robotic transthoracic esophagectomy in the prone position: experience with 32 patients with esophageal cancer. J Thorac Cardiovasc Surg. 2011;142(5): $1283-1284$.

39. Kassis ES, Kosinski AS, Ross P Jr, Koppes KE, Donahue JM, Daniel VC. Predictors of anastomotic leak after esophagectomy: an analysis of the society of thoracic surgeons general thoracic database. Ann Thorac Surg. 2013;96(6):1919-1926.

40. Sarkaria IS, Rizk NP, Finley DJ, et al. Combined thoracoscopic ansd laparoscopic robotic-assisted minimally invasive esophagectomy using a four-arm platform: experience, technique and cautions during early procedure development. Eur J Cardiothorac Surg. 2013;43(5): e107-e115.

41. Sarkaria IS, Rizk NP. Robotic-assisted minimally invasive esophagectomy: the Ivor Lewis approach. Thorac Surg Clin. 2014;24(2): 211-222, vii.

42. de la Fuente SG, Weber J, Hoffe SE, Shridhar R, Karl R, Meredith KL. Initial experience from a large referral center with robotic-assisted Ivor Lewis esophagogastrectomy for oncologic purposes. Surg Endosc. 2013;27(9):3339-3347. 
43. Cerfolio RJ, Bryant AS, Hawn MT. Technical aspects and early results of robotic esophagectomy with chest anastomosis. JThorac Cardiovasc Surg. 2013;145(1):90-96.

44. Trugeda S, Fernández-Díaz MJ, Rodríguez-Sanjuán JC, Palazuelos CM, Fernández-Escalante $\mathrm{C}$, Gómez-Fleitas $\mathrm{M}$. Initial results of robot-assisted Ivor-Lewis oesophagectomy with intrathoracic handsewn anastomosis in the prone position. Int J Med Robot. 2014;10(4): 397-403.

45. Dunn DH, Johnson EM, Morphew JA, Dilworth HP, Krueger JL, Banerji N. Robot-assisted transhiatal esophagectomy: a 3-year single-center experience. Dis Esophagus. 2013;26(2):159-166.

46. Clark J, Sodergren MH, Purkayastha S, et al. The role of robotic assisted laparoscopy for oesophagogastric oncological resection; an appraisal of the literature. Dis Esophagus. 2011;24(4):240-250.

47. Wei B, D'Amico TA. Thoracoscopic versus robotic approaches: advantages and disadvantages. Thorac Surg Clin. 2014;24(2):177-188.

48. van der Sluis PC, Ruurda JP, van der Horst S, et al. Robot-assisted minimally invasive thoraco-laparoscopic esophagectomy versus open transthoracic esophagectomy for resectable esophageal cancer, a randomized controlled trial (ROBOT trial). Trials. 2012 $13: 230$.

49. Hernandez JM, Dimou F, Weber J, et al. Defining the learning curve for robotic-assisted esophagogastrectomy. J Gastrointest Surg. 2013;17(8): 1346-1351.

50. Sharma B, Baxter N, Grantcharov T. Outcomes after laparoscopic techniques in major gastrointestinal surgery. Curr Opin Crit Care. 2010;16(4):371-376

51. Liang Y, Li G, Chen P, Yu J, Zhang C. Laparoscopic versus open gastrectomy for early distal gastric cancer: a meta-analysis. ANZ J Surg 2011;81(10):673-680.

52. Lee HJ, Yang HK. Laparoscopic gastrectomy for gastric cancer. Dig Surg. 2013;30(2):132-141.

53. Kim HH, Hyung WJ, Cho GS, et al. Morbidity and mortality of laparoscopic gastrectomy versus open gastrectomy for gastric cancer: an interim report - a phase III multicenter, prospective, randomized Trial (KLASS Trial). Ann Surg. 2010;251(3):417-420.

54. Uyama I, Suda K, Satoh S. Laparoscopic surgery for advanced gastric cancer: current status and future perspectives. J Gastric Cancer. 2013;13(1):19-25

55. Roviello F, Piagnerelli R, Ferrara F, Caputo E, Scheiterle M, Marrelli D. Assessing the feasibility of full robotic interaortocaval nodal dissection for locally advanced gastric cancer. Int J Med Robot. Epub April 15, 2014.

56. Heemskerk J, van Gemert WG, de Vries J, Greve J, Bouvy ND. Learning curves of robot-assisted laparoscopic surgery compared with conventional laparoscopic surgery: an experimental study evaluating skill acquisition of robot-assisted laparoscopic tasks compared with conventional laparoscopic tasks in inexperienced users. Surg Laparosc Endosc Percutan Tech. 2007;17(3):171-174.

57. Coratti A, Annecchiarico M, Di Marino M, Gentile E, Coratti F, Giulianotti PC. Robot-assisted gastrectomy for gastric cancer: current status and technical considerations. World J Surg. 2013;37(12): 2771-2781.

58. Hashizume M, Sugimachi K. Robot-assisted gastric surgery. Surg Clin North Am. 2003;83(6):1429-1444.

59. Hyun MH, Lee CH, Kim HJ, Tong Y, Park SS. Systematic review and meta-analysis of robotic surgery compared with conventional laparoscopic and open resections for gastric carcinoma. $\mathrm{Br} J$ Surg. 2013;100(12):1566-1578.

60. Suda K, Man-I M, Ishida Y, Kawamura Y, Satoh S, Uyama I. Potential advantages of robotic radical gastrectomy for gastric adenocarcinoma in comparison with conventional laparoscopic approach: a single institutional retrospective comparative cohort study. Surg Endosc. Epub July $17,2014$.

61. Xiong B, Ma L, Zhang C. Robotic versus laparoscopic gastrectomy for gastric cancer: a meta-analysis of short outcomes. Surg Oncol. 2012;21(4):274-280
62. Zong L, Seto Y, Aikou S, Takahashi T. Efficacy evaluation of subtotal and total gastrectomies in robotic surgery for gastric cancer compared with that in open and laparoscopic resections: a meta-analysis. PLoS One. 2014;9(7):e103312.

63. Kim KM, An JY, Kim HI, Cheong JH, Hyung WJ, Noh SH. Major early complications following open, laparoscopic and robotic gastrectomy. Br J Surg. 2012;99(12):1681-1687.

64. D'Annibale A, Pende V, Pernazza G, et al. Full robotic gastrectomy with extended (D2) lymphadenectomy for gastric cancer: surgical technique and preliminary results. J Surg Res. 2011;166(2):e113-e120.

65. Liu XX, Jiang ZW, Chen P, Zhao Y, Pan HF, Li JS. Full robot-assisted gastrectomy with intracorporeal robot-sewn anastomosis produces satisfying outcomes. World J Gastroenterol. 2013;19(38):6427-6437.

66. Son T, Lee JH, Kim YM, Kim HI, Noh SH, Hyung WJ. Robotic spleenpreserving total gastrectomy for gastric cancer: comparison with conventional laparoscopic procedure. Surg Endosc. 2014;28(9):2606-2615.

67. Song J, Oh SJ, Kang WH, Hyung WJ, Choi SH, Noh SH. Robot-assisted gastrectomy with lymph node dissection for gastric cancer: lessons learned from an initial 100 consecutive procedures. Ann Surg. 2009; 249(6):927-932.

68. Liao G, Chen J, Ren C, et al. Robotic versus open gastrectomy for gastric cancer: a meta-analysis. PLoS One. 2013;8(12):e81946.

69. Hyun $\mathrm{MH}$, Lee $\mathrm{CH}$, Kwon YJ, et al. Robot versus laparoscopic gastrectomy for cancer by an experienced surgeon: comparisons of surgery, complications, and surgical stress. Ann Surg Oncol. 2013;20(4): $1258-1265$.

70. Pugliese R, Maggioni D, Sansonna F, et al. Subtotal gastrectomy with D2 dissection by minimally invasive surgery for distal adenocarcinoma of the stomach: results and 5-year survival. Surg Endosc. 2010;24(10):2594-2602.

71. Park JY, Kim YW, Ryu KW, Eom BW, Yoon HM, Reim D. Emerging role of robot-assisted gastrectomy: analysis of consecutive 200 cases. $J$ Gastric Cancer. 2013;13(4):255-262.

72. Junfeng Z, Yan S, Bo T, et al. Robotic gastrectomy versus laparoscopic gastrectomy for gastric cancer: comparison of surgical performance and short-term outcomes. Surg Endosc. 2014;28(6):1779-1787.

73. Marano A, Hyung WJ. Robotic gastrectomy: the current state of the art. J Gastric Cancer. 2012;12(2):63-72.

74. Reich H, McGlynn F, DeCaprio J, Budin R. Laparoscopic excision of benign liver lesions. Obstet Gynecol. 1991;78(5):956-958.

75. Laurence JM, Lam VW, Langcake ME, Hollands MJ, Crawford MD, Pleass HC. Laparoscopic hepatectomy, a systematic review. ANZ J Surg. 2007;77(11):948-953.

76. Nguyen KT, Gamblin TC, Geller DA. World review of laparoscopic liver resection-2,804 patients. Ann Surg. 2009;250(5):831-841.

77. Vigano L, Tayar C, Laurent A, Cherqui D. Laparoscopic liver resection: a systematic review. J Hepatobiliary Pancreat Surg. 2009;16(4): 410-421.

78. Pilgrim CH, To H, Usatoff V, Evans PM. Laparoscopic hepatectomy is a safe procedure for cancer patients. $H P B$ (Oxford). 2009;11(3): $247-251$.

79. Mizuguchi T, Kawamoto M, Meguro M, et al. Laparoscopic hepatectomy: a systematic review, meta-analysis, and power analysis. Surg Today. 2011;41(1):39-47.

80. Buell JF, Cherqui D, Geller DA, et al; World Consensus Conference on Laparoscopic Surgery. The international position on laparoscopic liver surgery: The Louisville Statement, 2008. Ann Surg. 2009;250(5): 825-830.

81. Belli G, Gayet B, Han HS, et al. Laparoscopic left hemihepatectomy a consideration for acceptance as standard of care. Surg Endosc. 2013;27(8):2721-2726.

82. Dagher I, O’Rourke N, Geller DA, Cherqui D, Belli G, Gamblin TC. Laparoscopic major hepatectomy: an evolution in standard of care. Ann Surg. 2009;250(5):856-860.

83. Koffron AJ, Auffenberg G, Kung R, Abecassis M. Evaluation of 300 minimally invasive liver resections at a single institution: less is more. Ann Surg. 2007;246(3):385-392. 
84. Rao AM, Ahmed I. Laparoscopic versus open liver resection for benign and malignant hepatic lesions in adults. Cochrane Database Syst Rev. 2013;5:CD010162.

85. Boggi U, Moretto C, Vistoli F, D'Imporzano S, Mosca F. Robotic suture of a large caval injury caused by endo-GIA stapler malfunction during laparoscopic wedge resection of liver segments VII and VIII enbloc with the right hepatic vein. Minim Invasive Ther Allied Technol. 2009;18(5):306-310.

86. Shen BY, Zhan Q, Deng XX, et al. Radical resection of gallbladder cancer: could it be robotic? Surg Endosc. 2012;26(11): 3245-3250.

87. Lai EC, Yang GP, Tang CN. Robot-assisted laparoscopic liver resection for hepatocellular carcinoma: short-term outcome. Am J Surg. 2013;205(6):697-702.

88. Ho CM, Wakabayashi G, Nitta H, Ito N, Hasegawa Y, Takahara T. Systematic review of robotic liver resection. Surg Endosc. 2013;27(3): 732-739.

89. Giulianotti PC, Tzvetanov I, Jeon H, et al. Robot-assisted right lobe donor hepatectomy. Transpl Int. 2012;25(1):e5-e9.

90. Patriti A, Ceccarelli G, Bartoli A, Spaziani A, Lapalorcia LM, Casciola L. Laparoscopic and robot-assisted one-stage resection of colorectal cancer with synchronous liver metastases: a pilot study. J Hepatobiliary Pancreat Surg. 2009;16(4):450-457.

91. Giulianotti PC, Coratti A, Sbrana F, et al. Robotic liver surgery: results for 70 resections. Surgery. 2011;149(1):29-39.

92. Wakabayashi G, Sasaki A, Nishizuka S, Furukawa T, Kitajima M. Our initial experience with robotic hepato-biliary-pancreatic surgery. $J$ Hepatobiliary Pancreat Sci. 2011;18(4):481-487.

93. Choi GH, Choi SH, Kim SH, et al. Robotic liver resection: technique and results of 30 consecutive procedures. Surg Endosc. 2012;26(8): 2247-2258.

94. Wu YM, Hu RH, Lai HS, Lee HP. Robotic-assisted minimally invasive liver resection. Asian J Surg. 2014;37(2):53-57.

95. Pelletier JS, Gill RS, Shi X, Birch DW, Karmali S. Robotic-assisted hepatic resection: a systematic review. Int J Med Robot. 2013;9(3): 262-267.

96. Casciola L, Patriti A, Ceccarelli G, Bartoli A, Ceribelli C, Spaziani A. Robot-assisted parenchymal-sparing liver surgery including lesion located in the posterosuperior segments. Surg Endosc. 2011;25(12): 3815-3824.

97. Giulianotti PC, Sbrana F, Coratti A, et al. Totally robotic right hepatectomy: surgical technique and outcomes. Arch Surg. 2011; 146(7):844-850.

98. Lai EC, Tang CN, Li MK. Robot-assisted laparoscopic hemihepatectomy: technique and surgical outcomes. Int J Surg. 2012; 10(1):11-15.

99. Chan OC, Tang CN, Lai EC, Yang GP, Li MK. Robotic hepatobiliary and pancreatic surgery: a cohort study. J Hepatobiliary Pancreat Sci. 2011;18(4):471-480.

100. Berber E, Akyildiz HY, Aucejo F, Gunasekaran G, Chalikonda S, Fung J. Robotic versus laparoscopic resection of liver tumours. $H P B$ (Oxford). 2010;12(8):583-586.

101. Ji WB, Wang HG, Zhao ZM, Duan WD, Lu F, Dong JH. Robotic-assisted laparoscopic anatomic hepatectomy in China: initial experience. Ann Surg. 2011;253(2):342-348.

102. Spampinato MG, Coratti A, Bianco L, et al. Perioperative outcomes of laparoscopic and robot-assisted major hepatectomies: an Italian multi-institutional comparative study. Surg Endosc. 2014;28(10): 2973-2979.

103. Tsung A, Geller DA, Sukato DC, et al. Robotic versus laparoscopic hepatectomy: a matched comparison. Ann Surg. 2014;259(3): 549-555.

104. Tranchart H, Ceribelli C, Ferretti S, Dagher I, Patriti A. Traditional versus robot-assisted full laparoscopic liver resection: a matched-pair comparative study. World J Surg. 2014;38(11):2904-2909.

105. Kim JH, Baek NH, Li G, et al. Robotic cholecystectomy with new port sites. World J Gastroenterol. 2013;19(20):3077-3082.
106. Vidovszky TJ, Carr AD, Farinholt GN, Ho HS, Smith WH, Ali MR. Single-site robotic cholecystectomy in a broadly inclusive patient population: a prospective study. Ann Surg. 2014;260(1):134-141.

107. Spinoglio G, Priora F, Bianchi PP, et al. Real-time near-infrared (NIR) fluorescent cholangiography in single-site robotic cholecystectomy (SSRC): a single-institutional prospective study. Surg Endosc. 2013;27(6):2156-2162.

108. Kwon W, Jang JY, Park JW, Han IW, Kang MJ, Kim SW. Which method of pancreatic surgery do medical consumers prefer among open, laparoscopic, or robotic surgery? A survey. Ann Surg Treat Res. 2014;86(1):7-15.

109. Rosales-Velderrain A, Bowers SP, Goldberg RF, et al. National trends in resection of the distal pancreas. World J Gastroenterol. 2012;18(32):4342-4349.

110. Ejaz A, Sachs T, He J, et al. A comparison of open and minimally invasive surgery for hepatic and pancreatic resections using the nationwide inpatient sample. Surgery. 2014;156(3):538-547.

111. Jayaraman S, Gonen M, Brennan MF, et al. Laparoscopic distal pancreatectomy: evolution of a technique at a single institution. $J \mathrm{Am}$ Coll Surg. 2010;211(4):503-509.

112. Pericleous S, Middleton N, McKay SC, Bowers KA, Hutchins RR. Systematic review and meta-analysis of case-matched studies comparing open and laparoscopic distal pancreatectomy: is it a safe procedure? Pancreas. 2012;41(7):993-1000.

113. Venkat R, Edil BH, Schulick RD, Lidor AO, Makary MA, Wolfgang CL. Laparoscopic distal pancreatectomy is associated with significantly less overall morbidity compared to the open technique: a systematic review and meta-analysis. Ann Surg. 2012;255(6):1048-1059.

114. Fox AM, Pitzul K, Bhojani F, et al. Comparison of outcomes and costs between laparoscopic distal pancreatectomy and open resection at a single center. Surg Endosc. 2012;26(5):1220-1230.

115. Kudsi OY, Gagner M, Jones DB. Laparoscopic distal pancreatectomy. Surg Oncol Clin N Am. 2013;22(1):59-73.

116. Kendrick ML, Cusati D. Total laparoscopic pancreaticoduodenectomy: feasibility and outcome in an early experience. Arch Surg. 2010;145(1): 19-23.

117. Ammori BJ, Ayiomamitis GD. Laparoscopic pancreaticoduodenectomy and distal pancreatectomy: a UK experience and a systematic review of the literature. Surg Endosc. 2011;25(7):2084-2099.

118. Corcione F, Pirozzi F, Cuccurullo D, et al. Laparoscopic pancreaticoduodenectomy: experience of 22 cases. Surg Endosc. 2013;27(6):2131-2136.

119. Croome KP, Farnell MB, Que FG, et al. Total laparoscopic pancreaticoduodenectomy for pancreatic ductal adenocarcinoma: oncologic advantages over open approaches? Ann Surg. 2014;260(4):633-638; discussion 638-640.

120. Correa-Gallego C, Dinkelspiel HE, Sulimanoff I, et al. Minimallyinvasive vs open pancreaticoduodenectomy: systematic review and meta-analysis. J Am Coll Surg. 2014;218(1):129-139.

121. Lei P, Wei B, Guo W, Wei H. Minimally invasive surgical approach compared with open pancreaticoduodenectomy: a systematic review and meta-analysis on the feasibility and safety. Surg Laparosc Endosc Percutan Tech. 2014;24(4):296-305.

122. Giulianotti PC, Sbrana F, Bianco FM, et al. Robot-assisted laparoscopic pancreatic surgery: single-surgeon experience. Surg Endosc. 2010;24(7):1646-1657.

123. Choi SH, Kang CM, Lee WJ, Chi HS. Robot-assisted spleenpreserving laparoscopic distal pancreatectomy. Ann Surg Oncol. 2011;18(13):3623.

124. Horiguchi A, Uyama I, Miyakawa S. Robot-assisted laparoscopic pancreaticoduodenectomy. J Hepatobiliary Pancreat Sci. 2011;18(2): 287-291.

125. Zeh HJ, Zureikat AH, Secrest A, Dauoudi M, Bartlett D, Moser AJ. Outcomes after robot-assisted pancreaticoduodenectomy for periampullary lesions. Ann Surg Oncol. 2012;19(3):864-870.

126. Coratti A, Annecchiarico M. Robot-assisted pancreatic surgery. $\mathrm{Br} J$ Surg. 2014;101(6):593-594. 
127. Narula VK, Mikami DJ, Melvin WS. Robotic and laparoscopic pancreaticoduodenectomy: a hybrid approach. Pancreas. 2010;39(2): $160-164$.

128. Lai EC, Yang GP, Tang CN. Robot-assisted laparoscopic pancreaticoduodenectomy versus open pancreaticoduodenectomy: a comparative study. Int J Surg. 2012;10(9):475-479.

129. Daouadi M, Zureikat AH, Zenati MS, et al. Robot-assisted minimally invasive distal pancreatectomy is superior to the laparoscopic technique. Ann Surg. 2013;257(1):128-132.

130. Zureikat AH, Moser AJ, Boone BA, Bartlett DL, Zenati M, Zeh HJ 3rd. 250 robotic pancreatic resections: safety and feasibility. Ann Surg. 2013;258(4):554-559; discussion 559-562.

131. Boggi U, Signori S, De Lio N, et al. Feasibility of robotic pancreaticoduodenectomy. Br J Surg. 2013;100(7):917-925.

132. Boggi U, Palladino S, Massimetti G, et al. Laparoscopic robot-assisted versus open total pancreatectomy: a case-matched study. Surg Endosc. Epub August 27, 2014.

133. Gagner M, Palermo M. Laparoscopic Whipple procedure: review of the literature. J Hepatobiliary Pancreat Surg. 2009;16(6) 726-730.

134. Asbun HJ, Stauffer JA. Laparoscopic vs open pancreaticoduodenectomy: overall outcomes and severity of complications using the Accordion Severity Grading System. J Am Coll Surg. 2012;215(6):810-819.

135. Zhang J, Wu WM, You L, Zhao YP. Robotic versus open pancreatectomy: a systematic review and meta-analysis. Ann Surg Oncol. 2013;20(6):1774-1780.

136. Cirocchi R, Partelli S, Trastulli S, Coratti A, Parisi A, Falconi M. A systematic review on robotic pancreaticoduodenectomy. Surg Oncol. 2013;22(4):238-246.

137. Parisi A, Coratti F, Cirocchi R, et al. Robotic distal pancreatectomy with or without preservation of spleen: a technical note. World J Surg Oncol. 2014;12:295.

138. Kang CM, Lee SH, Lee WJ. Minimally invasive radical pancreatectomy for left-sided pancreatic cancer: current status and future perspectives. World J Gastroenterol. 2014;20(9):2343-2351.

139. Lee SH, Kang CM, Hwang HK, Choi SH, Lee WJ, Chi HS. Minimally invasive RAMPS in well-selected left-sided pancreatic cancer within Yonsei criteria: long-term (>median 3 years) oncologic outcomes. Surg Endosc. 2014;28(10):2848-2855.

140. Del Chiaro M, Segersvärd R. The state of the art of robotic pancreatectomy. Biomed Res Int. 2014;2014:920492.

141. Hwang HK, Kang CM, Chung YE, Kim KA, Choi SH, Lee WJ. Robot-assisted spleen-preserving distal pancreatectomy: a single surgeon's experiences and proposal of clinical application. Surg Endosc. 2013;27(3):774-781.

142. Martel G, Boushey RP. Laparoscopic colon surgery: past, present and future. Surg Clin North Am. 2006;86(4):867-897.

143. Aly EH. Colorectal surgery: current practice and future developments. Int J Surg. 2012;10(4):182-186.

144. Lacy AM, García-Valdecasas JC, Delgado S, et al. Laparoscopy-assisted colectomy versus open colectomy for treatment of non-metastatic colon cancer: a randomised trial. Lancet. 2002;359(9325):2224-2229.

145. Clinical Outcomes of Surgical Therapy Study Group. A comparison of laparoscopically assisted and open colectomy for colon cancer N Engl J Med. 2004;350(20):2050-2059.

146. Veldkamp R, Kuhry E, Hop WC, et al; COlon cancer Laparoscopic or Open Resection Study Group (COLOR). Laparoscopic surgery versus open surgery for colon cancer: short-term outcomes of a randomised trial. Lancet Oncol. 2005;6(7):477-484.

147. Guillou PJ, Quirke P, Thorpe H, et al; MRC CLASICC trial group. Shortterm endpoints of conventional versus laparoscopic-assisted surgery in patients with colorectal cancer (MRC CLASICC trial): multicentre, randomised controlled trial. Lancet. 2005;365(9472):1718-1726.

148. Hewett PJ, Allardyce RA, Bagshaw PF, et al. Short-term outcomes of the Australasian randomized clinical study comparing laparoscopic and conventional open surgical treatments for colon cancer: the ALCCaS trial. Ann Surg. 2008;248(5):728-738.
149. Fleshman J, Sargent DJ, Green E, et al; Clinical Outcomes of Surgical Therapy Study Group. Laparoscopic colectomy for cancer is not inferior to open surgery based on 5-year data from the COST Study Group trial. Ann Surg. 2007;246(4):655-662; discussion 662-664.

150. Lacy AM, Delgado S, Castells A, et al. The long term results of a randomized clinical trial of laparoscopy-assisted versus open surgery for colon cancer. Ann Surg. 2008;248(1):1-7.

151. Colon Cancer Laparoscopic or Open Resection Study Group; Buunen M, Veldkamp R, Hop WC, et al. Survival after laparoscopic surgery versus open surgery for colon cancer: long-term outcome of a randomised clinical trial. Lancet Oncol. 2009;10(1):44-52.

152. Jayne DG, Thorpe HC, Copeland J, Quirke P, Brown JM, Guillou PJ. Five-year follow-up of the Medical Research Council CLASICC trial of laparoscopically assisted versus open surgery for colorectal cancer Br J Surg. 2010;97(11):1638-1645.

153. Bagshaw PF, Allardyce RA, Frampton CM, et al; Australasian Laparoscopic Colon Cancer Study Group. Long-term outcomes of the Australasian randomized clinical trial comparing laparoscopic and conventional open surgical treatments for colon cancer: the Australasian Laparoscopic Colon Cancer Study trial. Ann Surg. 2012;256(6):915-919.

154. Schwenk W, Haase O, Neudecker J, Müller JM. Short term benefits for laparoscopic colorectal resection. Cochrane Database Syst Rev. 2005;20(3):CD003145

155. Bonjer HJ, Hop WC, Nelson H, et al; Transatlantic Laparoscopically Assisted vs Open Colectomy Trials Study Group. Laparoscopically assisted vs open colectomy for colon cancer: a meta-analysis. Arch Surg. 2007;142(3):298-303.

156. Kuhry E, Schwenk WF, Gaupset R, Romild U, Bonjer HJ. Long-term results of laparoscopic colorectal cancer resection. Cochrane Database Syst Rev. 2008;16(2):CD003432.

157. Breukink S, Pierie J, Wiggers T. Laparoscopic versus open total mesorectal excision for rectal cancer. Cochrane Database Syst Rev. 2006;(4):CD005200.

158. van der Pas MH, Haglind E, Cuesta MA, et al; COlorectal cancer Laparoscopic or Open Resection II (COLOR II) Study Group. Laparoscopic versus open surgery for rectal cancer (COLOR II): short-term outcomes of a randomised, phase 3 trial. Lancet Oncol. 2013;14(3):210-218

159. Kang SB, Park JW, Jeong SY, et al. Open versus laparoscopic surgery for mid or low rectal cancer after neoadjuvant chemoradiotherapy (COREAN trial): short-term outcomes of an open-label randomised controlled trial. Lancet Oncol. 2010;11(11):637-645.

160. Lujan J, Valero G, Biondo S, Espin E, Parrilla P, Ortiz H. Laparoscopic versus open surgery for rectal cancer: results of a prospective multicentre analysis of 4,970 patients. Surg Endosc. 2013;27(1): 295-302.

161. Vennix S, Pelzers L, Bouvy N, et al. Laparoscopic versus open total mesorectal excision for rectal cancer. Cochrane Database Syst Rev. 2014;4:CD005200

162. Tekkis PP, Senagore AJ, Delaney CP, Fazio VW. Evaluation of the learning curve in laparoscopic colorectal surgery: comparison of right sided and left sided resections. Ann Surg. 2005;242(1):83-91.

163. Schlachta CM, Mamazza J, Seshadri PA, Cadeddu M, Gregoire R, Poulin EC. Defining a learning curve of laparoscopic colorectal resections. Dis Colon Rectum. 2001;44(2):217-222.

164. Bell MC, Torgerson JL, Kreaden U. The first 100 da Vinci hysterectomies: an analysis of the learning curve for a single surgeon. S D Med. 2009;62(3):91, 93-95.

165. Bokhari MB, Patel CB, Ramos Valadez DI, Ragupathi M, Haas EM. Learning curve for robotic-assisted laparoscopic colorectal surgery. Surg Endosc. 2011;25(3):855-860.

166. deSouza A, Prasad LM, Marecik SJ, et al. Total mesorectal excision for rectal cancer: the potential advantage of robotic assistance. Dis Colon Rectum. 2010;53(12):1611-1617.

167. Weber P, Merola S, Wasielewski A, Ballantyne G. Telerobotic-assisted laparoscopic right and sigmoid colectomies for benign disease. Dis Colon Rectum. 2002;45(12):1689-1696. 
168. Patel CB, Ragupathi M, Ramos-Valadez DI, Haas EM. A three-arm (laparoscopic, hand-assisted, and robotic) matched-case analysis of intraoperative and postoperative outcomes in minimally invasive colorectal surgery. Dis Colon Rectum. 2011;54(2):144-150.

169. Deutsch GB, Sathyanarayana SA, Gunabushanam V, et al. Robotic vs laparoscopic colorectal surgery: an institutional experience. Surg Endosc. 2012;26(4):956-963.

170. Fung AK, Aly EH. Robotic colonic surgery: is it advisable to commence a new learning curve? Dis Colon Rectum. 2013;56(6):786-796.

171. Halabi WJ, Kang CY, Jafari MD, et al. Robotic-assisted colorectal surgery in the United States: a nationwide analysis of trends and outcomes. World J Surg. 2013;37(12):2782-2790.

172. Roscio F, Bertoglio C, DeLuca A, Frattini P, Scandroglio I. Totally laparoscopic versus laparoscopic assisted right colectomy for cancer. Int J Surg. 2012;10(6):290-295.

173. Baek SK, Carmichael JC, Pigazzi A. Robotic surgery: colon and rectum. Cancer J. 2013;19(2):140-146.

174. Witkiewicz W, Zawadzki M, Rząca M, et al. Robot-assisted right colectomy: surgical technique and review of the literature. Wideochir Inne Tech Malo Inwazyjne. 2013;8(3):253-257.

175. Ballantyne GH, Ewing D, Pigazzi A, Wasielewski A. Telerobotic assisted laparoscopic right hemicolectomy: lateral to medial or medial to lateral dissection? Surg Laparosc Endosc Percutan Tech. 2006;16(6):406-410.

176. deSouza A, Prasad LM, Park JJ, Marecik SJ, Blumetti J, Abcarian H. Robotic assistance in right hemicolectomy: is there a role? Dis Colon Rectum. 2010;53(7):1000-1006.

177. Park JS, Choi GS, Park SY, Kim HJ, Ryuk JP. Randomized clinical trial of robot-assisted versus standard laparoscopic right colectomy. Br J Surg. 2012;99(9):1218-1226.

178. D'Annibale A, Pernazza G, Morpurgo E, et al. Robotic right colon resection: evaluation of first 50 consecutive cases for malignant disease. Ann Surg Onc. 2010;17(11):2856-2862.

179. Bianchi PP, Pigazzi A, Choi SG. Clinical Robotic Surgery Association Fifth Worldwide Congress, Washington DC, 3-5 October 2013: Robotic Colorectal Surgery. Ecancermedicalscience. 2014;8:385.

180. Rawlings AL, Woodland JH, Vegunta RK, Crawford DL. Robotic versus laparoscopic colectomy. Surg Endosc. 2007;21(10):1701-1708.

181. Mirnezami AH, Mirnezami R, Venkatasubramaniam AK, Chandrakumaran K, Cecil TD, Moran BJ. Robotic colorectal surgery: hype or new hope? A systematic review of robotics in colorectal surgery. Colorectal Dis. 2010;12(11):1084-1093.

182. Kanji A, Gill RS, Shi X, Birch DW, Karmali S. Robotic-assisted colon and rectal surgery: a systematic review. Int $J$ Med Robot. 2011;7(4):401-407.

183. Jiménez Rodríguez RM, Díaz Pavón JM, de La Portilla de Juan F, et al. Estudio prospectivo, aleatorizado: cirugía laparoscópica con asistencia robótica versus cirugía laparoscópica convencional en la resección del cáncer colorectal [Prospective randomised study: robotic-assisted versus conventional laparoscopic surgery in colorectal cancer resection]. Cir Esp. 2011;89(7):432-438. Spanish.

184. Kim SH, Kwak JM. Robotic total mesorectal excision: operative technique and review of the literature. Tech Coloproctol. 2013; 17 Suppl 1:S47-S53.

185. Baik SH, Kwon HY, Kim JS, et al. Robotic versus laparoscopic low anterior resection of rectal cancer: short-term outcome of a prospective comparative study. Ann Surg Oncol. 2009;16(6):1480-1487.

186. Hara M, Yoo BE, Shin JW, Lee DW, Kim SH. Robotic-assisted surgery for rectal adenocarcinoma: short-term and midterm outcomes from 200 consecutive cases at a single institution. Dis Colon Rectum. 2014;57(5):570-577.

187. Park JS, Choi GS, Lim KH, Jang YS, Jun SH. S052: a comparison of robot-assisted, laparoscopic, and open surgery in the treatment of rectal cancer. Surg Endosc. 2011;25(1):240-248.

188. Patriti A, Ceccarelli G, Bartoli A, Spaziani A, Biancafarina A, Casciola L. Short- and medium-term outcome of robot-assisted and traditional laparoscopic rectal resection. JSLS. 2009;13(2):176-183.
189. Baek JH, Pastor C, Pigazzi A. Robotic and laparoscopic total mesorectal excision for rectal cancer: a case-matched study. Surg Endosc. 2011;25(2):521-525.

190. Park IJ, You YN, Schlette E, et al. Reverse-hybrid robotic mesorectal excision for rectal cancer. Dis Colon Rectum. 2012;55(2):228-233.

191. Fernandez R, Anaya DA, Li LT, et al. Laparoscopic versus robotic rectal resection for rectal cancer in a veteran population. Am J Surg. 2013;206(4):509-517.

192. Ng KH, Lim YK, Ho KS, Ooi BS, Eu KW. Robotic- assisted surgery for low rectal dissection: from better views to better outcome. Singapore Med J. 2009;50(8):763-767.

193. Koh DC, Tsang CB, Kim SH. A new application of the four-arm standard da Vinci surgical system: totally robotic-assisted left-sided colon or rectal resection. Surg Endosc. 2011;25(6):1945-1952.

194. Leong QM, Son DN, Cho JS, et al. Robot-assisted intersphincteric resection for low rectal cancer: technique and short term outcome for 29 consecutive patients. Surg Endosc. 2011;25(9):2987-2992.

195. Pucci MJ, Beekley AC. Use of robotics in colon and rectal surgery. Clin Colon Rectal Surg. 2013;26(1):39-46.

196. Erguner I, Aytac E, Boler DE, et al. What have we gained by performing robotic rectal resection? Evaluation of 64 consecutive patients who underwent laparoscopic or robotic low anterior resection for rectal adenocarcinoma. Surg Laparosc Endosc Percutan Tech. 2013;23(3): 316-319.

197. Bianchi PP, Ceriani C, Locatelli A, et al. Robotic versus laparoscopic total mesorectal excision for rectal cancer: a comparative analysis of oncological safety and short-term outcomes. Surg Endosc. 2010;24(11):2888-2894.

198. Shin JY. Comparison of short-term surgical outcomes between a robotic colectomy and a laparoscopic colectomy during early experience. J Korean Soc Coloproctol. 2012;28(1):19-26.

199. Park SY, Choi GS, Park JS, Kim HJ, Ryuk JP. Short-term clinical outcome of robot-assisted intersphinteric resection for low rectal cancer: a retrospective comparison with conventional laparoscopy. Surg Endosc. 2013;27(1):48-55.

200. Ghezzi TL, Luca F, Valvo M, et al. Robotic versus open total mesorectal excision for rectal cancer: comparative study of short and long-term outcomes. Eur J Surg Oncol. 2014;40(9):1072-1079.

201. Kwak JM, Kim SH, Kim J, Son DN, Baek SJ, Cho JS. Robotic vs laparoscopic resection of rectal cancer: short-term outcomes of a case-control study. Dis Colon Rectum. 2011;54(2):151-156.

202. Kang J, Yoon KJ, Min B, et al. The impact of robotic surgery for mid and low rectal cancer: a case matched analysis of a 3-arm comparison-open, laparoscopic, and robotic surgery. Ann Surg. 2013;257(1): 95-101.

203. Baek SJ, Kim SH, Cho JS, Shin JW, Kim J. Robotic versus conventional laparoscopic surgery for rectal cancer: a cost analysis from a single institute in Korea. World J Surg. 2012;36(11):2722-2729.

204. Helvind NM, Eriksen JR, Mogensen A, et al. No differences in shortterm morbidity and mortality after robot-assisted laparoscopic versus laparoscopic resection for colonic cancer: a case-control study of 263 patients. Surg Endosc. 2013;27(10):2575-2580.

205. Baek JH, McKenzie S, Garcia-Aguilar J, Pigazzi A. Oncologic outcomes of robotic-assisted total mesorectal excision for the treatment of rectal cancer. Ann Surg. 2010;251(5):882-886.

206. Collinson FJ, Jayne DG, Pigazzi A, et al. An international, multicentre, prospective, randomised, controlled, unblinded, parallel-group trial of robotic-assisted versus standard laparoscopic surgery for the curative treatment of rectal cancer. Int J Colorectal Dis. 2012;27(2): 233-241.

207. Pigazzi A, Luca F, Patriti A, et al. Multicentric study on robotic tumorspecific mesorectal excision for the treatment of rectal cancer. Ann Surg Oncol. 2010;17(6):1614-1620.

208. D'Annibale A, Morpurgo E, Fiscon V, et al. Robotic and laparoscopic surgery for treatment of colorectal diseases. Dis Colon Rectum. 2004;47(12):2162-2168

209. Speicher PJ, Englum BR, Ganapathi AM, Nussbaum DP, Mantyh CR, Migaly J. Robotic low anterior resection for rectal cancer: a national perspective on short-term oncologic outcomes. Ann Surg. Epub November 17, 2014. 
210. Bardakcioglu O. Robotic transanal access surgery. Surg Endosc. 2013;27(4):1407-1409.

211. Buchs NC, Pugin F, Volonte F, Hagen ME, Morel P, Ris F. Robotic transanal endoscopic microsurgery: technical details for the lateral approach. Dis Colon Rectum. 2013;56(10):1194-1198.

212. Hompes R, Rauh SM, Ris F, Tuynman JB, Mortensen NJ. Robotic transanal minimally invasive surgery for local excision of rectal neoplasms. Br J Surg. 2014;101(5):578-581.

213. Canda AE, Atmaca AF, Altinova S, Akbulut Z, Balbay MD. Robot-assisted nerve-sparing radical cystectomy with bilateral extended pelvic lymph node dissection (PLND) and intracorporeal urinary diversion for bladder cancer: initial experience in 27 cases. BJU Int. 2012;110(3):434-444.

214. Talamini MA. Laparoscopy for benign disease: robotics. Semin Laparosc Surg. 2003;10(4):203-208.

215. Sanchez BR, Mohr CJ, Morton JM, Safadi BY, Alami RS, Curet MJ. Comparison of totally robotic laparoscopic Roux-en-Y gastric bypass and traditional laparoscopic Roux-en-Y gastric bypass. Surg Obes Relat Dis. 2005;1(6):549-554.

216. Cirocchi R, Boselli C, Santoro A, et al. Current status of robotic bariatric surgery: a systematic review. BMC Surg. 2013;13:53.

217. Bailey JG, Hayden JA, Davis PJ, Liu RY, Haardt D, Ellsmere J. Robotic versus laparoscopic Roux-en-Y gastric bypass (RYGB) in obese adults ages 18 to 65 years: a systematic review and economic analysis. Surg Endosc. 2014;28(2):414-426.

218. Paraiso MF, Jelovsek JE, Frick A, Chen CC, Barber MD. Laparoscopic compared with robotic sacrocolpopexy for vaginal prolapse: a randomized controlled trial. Obstet Gynecol. 2011;118(5):1005-1013.

219. Anger JT, Mueller ER, Tarnay C, et al. Robotic compared with laparoscopic sacrocolpopexy: a randomized controlled trial. Obstet Gynecol. 2014;123(1):5-12.

220. Zygomalas A, Kehagias I, Giokas K, Koutsouris D. Miniature surgical robots in the era of NOTES and LESS: dream or reality? Surg Innov. Epub May 14, 2014.
221. Idrees K, Barlett DL. Robotic liver surgery. Surg Clin North Am. 2010;90(4):761-774.

222. Diana M, Noll E, Diemunsch P, et al. Enhanced-reality video fluorescence: a real-time assessment of intestinal viability. Ann Surg. 2014;259(4):700-707.

223. Daskalaki D, Fernandes E, Wang X, et al. Indocyanine green (ICG) fluorescent cholangiography during robotic cholecystectomy: results of 184 consecutive cases in a single institution. Surg Innov. 2014;21(6): $615-621$

224. Sinno AK, Fader AN, Roche KL, Giuntoli RL 2nd, Tanner EJ. A comparison of colorimetric versus fluorometric sentinel lymph node mapping during robotic surgery for endometrial cancer. Gynecol Oncol. 2014;134(2):281-286.

225. Siddighi S, Yune JJ, Hardesty J. Indocyanine green for intraoperative localization of ureter. Am J Obstet Gynecol. 2014;211(4):436. e1-e2.

226. Hellan M, Spinoglio G, Pigazzi A, Lagares-Garcia JA. The influence of fluorescence imaging on the location of bowel transection during robotic left-sided colorectal surgery. Surg Endosc. 2014;28(5): $1695-1702$.

227. Marescaux J, Leroy J, Rubino F, et al. Transcontinental robot-assisted remote telesurgery: feasibility and potential applications. Ann Surg. 2002;235(4):487-492.

228. Mucksavage P, Kerbl DC, Lee JY. The da Vinci Surgical System ${ }^{\circledR}$ overcomes innate hand dominance. J Endourol. 2011;25(8): $1385-1388$.

229. Maniar HS, Council ML, Prasad SM, Prasad SM, Chu C, Damiano RJ Jr Comparison of skill training with robotic systems and traditional endoscopy: implications on training and adoption. J Surg Res. 2011;125(1):23-29.
Robotic Surgery: Research and Reviews

\section{Publish your work in this journal}

Robotic Surgery: Research and Reviews is an international, peer reviewed, open access, online journal publishing original research, commentaries, reports, and reviews on the theory, use and application of robotics in surgical interventions. Articles on the use of supervisory-controlled robotic systems, telesurgical devices, and shared-control systems are

\section{Dovepress}

invited. The manuscript management system is completely online and includes a very quick and fair peer review system, which is all easy to use. Visit http://www.dovepress.com/testimonials.php to read real quotes from published authors. 